\title{
Asymptomatic bilateral chemodectomas: a masquerader of simple neck masses
}

\author{
Pawar NC ${ }^{1}$, Sharma $S^{2}, \operatorname{Kaur~NK}{ }^{3}$, Kaur A ${ }^{4}$ \\ ${ }^{1}$ Dr Naveen Chandrashekhar Pawar, Junior Resident, ${ }^{2}$ Dr Shivani Sharma, Junior Resident, ${ }^{3}$ Dr Navkiran Kaur, Professor \\ and Head, ${ }^{4}$ Dr Amarjit Kaur, Professor; all authors are affiliated with department of Radio Diagnosis, Government \\ Medical College \& Rajindra Hospital, Patiala, Punjab, India
}

Address for correspondence: Dr Naveen Chandrashekhar Pawar, Email: naveencp27@gmail.com

\begin{abstract}
Patients presenting with asymptomatic neck masses to surgical OPD can have many differentials, ranging from the simplest reactive lymph nodes to aggressive malignant masses. Bilateral neck masses in a patient can be due to infective lymph nodes, salivary gland pathology, solid - cystic lesions of the neck and malignancies. Based on the anatomical site of the lesion, clinical examination still remains the first step in characterising the lesion into solid, cystic, pulsatile, non pulsatile, response to cough impulse and so on. Imaging is always a mandatory next step for the confirmation of diagnosis and to know about the morphology of the lesion with finer details. USG, CT and MRI are indispensable tools in assessing neck masses with equivocal findings on clinical examination and particularly in asymptomatic individuals where there is lack of history and thus diagnosis becomes a challenging task. One such entity is bilateral Chemodectomas where imaging plays a pivotal role in the diagnosis. We report a case of bilateral neck masses in an asymptomatic female patient which on imaging was diagnosed as a case of bilateral carotid body tumours and referred to higher centre for further management.
\end{abstract}

Key words: Splaying of carotid vessels, Extraadrenal Paraganglioma, Vanillylmandelic acid, Neck mass

\section{Introduction}

Carotid body tumours or carotid paragangliomas, a rare neoplasm, constitute $65 \%$ of head \& neck paragangliomas [1]. These arise from the sympathetic fibres of carotid bifurcation and are slow in growth [2]. Initially asymptomatic, these present as neck masses in most patients [3, 4]. Keeping in view the rarity of this tumour, it is often the last differential that comes to mind in a patient with neck swelling. Proper imaging is essential to prevent hazardous bleed during the process of investigations and hence complications.

\section{Case Presentation}

A 35 year old female presented to ENT OPD with history of bilateral neck swellings in submandibular region since 6 years. Swellings were gradually progressive in size. She complained of pain and stiffness in neck radiating to temporal region which was not worrisome and relived by taking "on the counter" pain killers. There was no history of local pain or redness. Patient did not complain of dysphagia, dysphonia, dyspnoea or weight loss. There was no history of any imaging in past or consultation for the same, all though our patient had 2 blind FNAC's done previously at her local place under the suspicion of submandibular gland / thyroid gland / nodal swellings, the results of which were not documented and fortunate for the patient as nothing inadvertent resulted following FNA. On examination the swellings were firm, slightly mobile and non tender. Cough impulse was negative and no bruit was heard on auscultation. The blood pressure was 140/90mm Hg i.e. slightly on the higher side, rest of the vitals were within normal limit. Her routine blood and urine tests

Manuscript received: $17^{\text {th }}$ December 2016

Reviewed: $26^{\text {th }}$ December 2016

Author Corrected: $05^{\text {th }}$ January 2017

Accepted for Publication: $12^{\text {th }}$ January 2017 
were normal. IDL examination did not reveal any significant abnormality except mild pooling of secretions in the right vallecula and pyriform fossa. Sytemic examination was unremarkable. Following this patient was referred to radiology department for investigations.

On ultrasound, 2 oval shaped heterogeneous predominantly hypoechoic masses were seen on either side, occupying the region of carotid bifurcations. The lesions measured $1.6 \times 2.2 \mathrm{~cm}$ and $2.6 \times 2.7 \mathrm{~cm}$ on right \& left side respectively [Figure 1].

Colour Doppler revealed vascular nature of lesions [Figure 2].

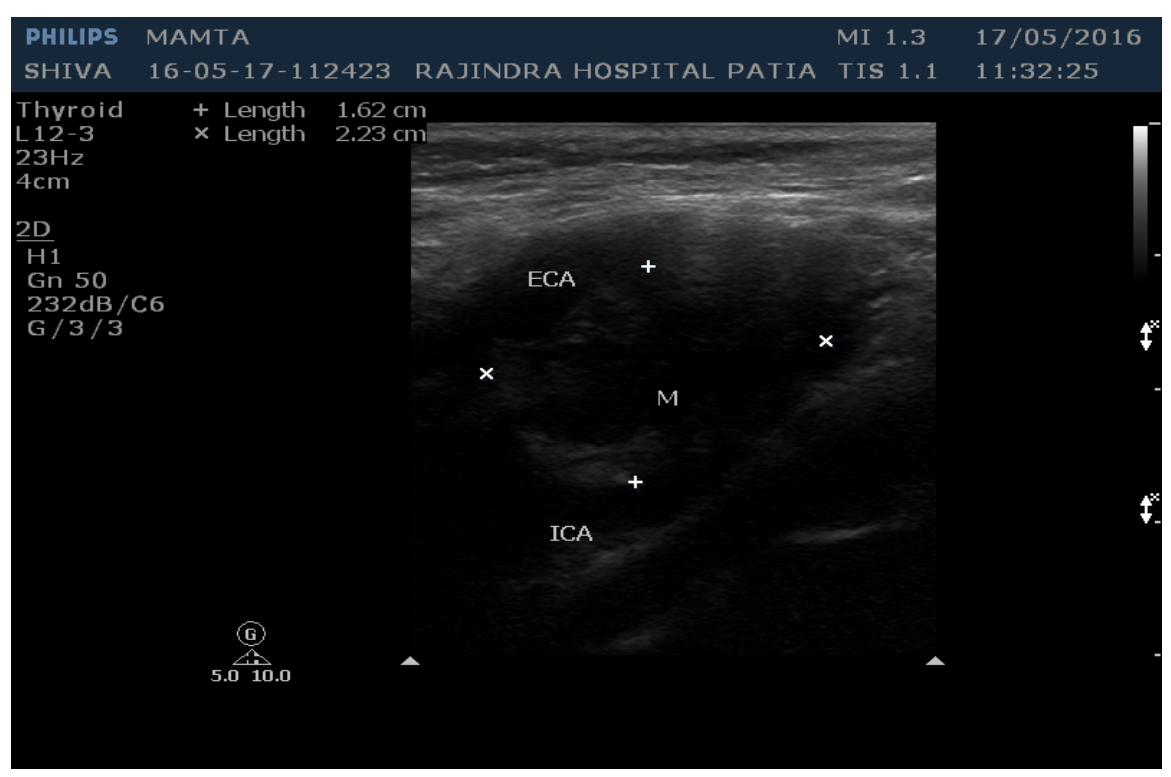

Figure-1: Longitudinal gray scale high resolution ultrasound image showing heterogeneous predominantly hypoechoic mass in the region of carotid bifurcation on right side

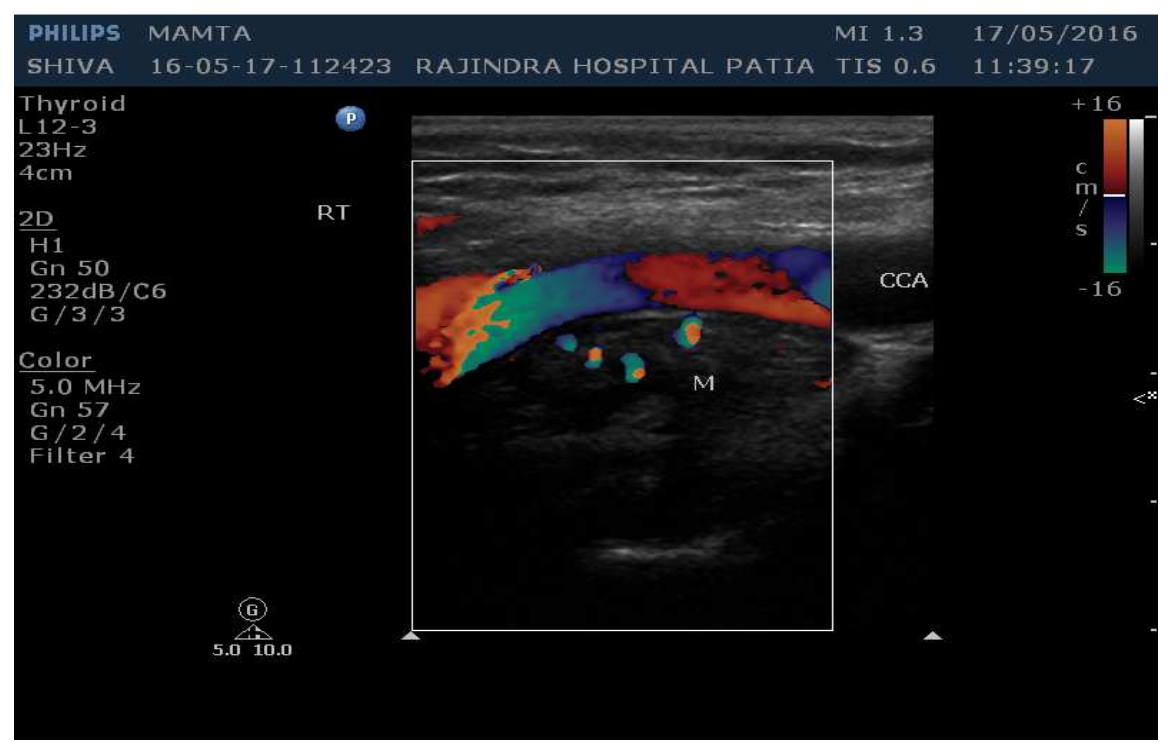

Figure-2: Longitudinal high resolution colour doppler USG showing the hypoechoic mass and carotid vessels on the right side

A provisional diagnosis of bilateral carotid body tumour / vagal paraganglioma was done and the patient was taken up for CT carotid angiography (CTA) and MRI. 
On CTA, the lesions were seen as intensely enhancing lobulated masses in the carotid bifurcation bilaterally. The internal and external carotid vessels were encased by the lesions along with characteristic splaying. The IJVs were displaced laterally. No involvement of skull base was seen. Few insignificant size cervical lymph nodes were seen.

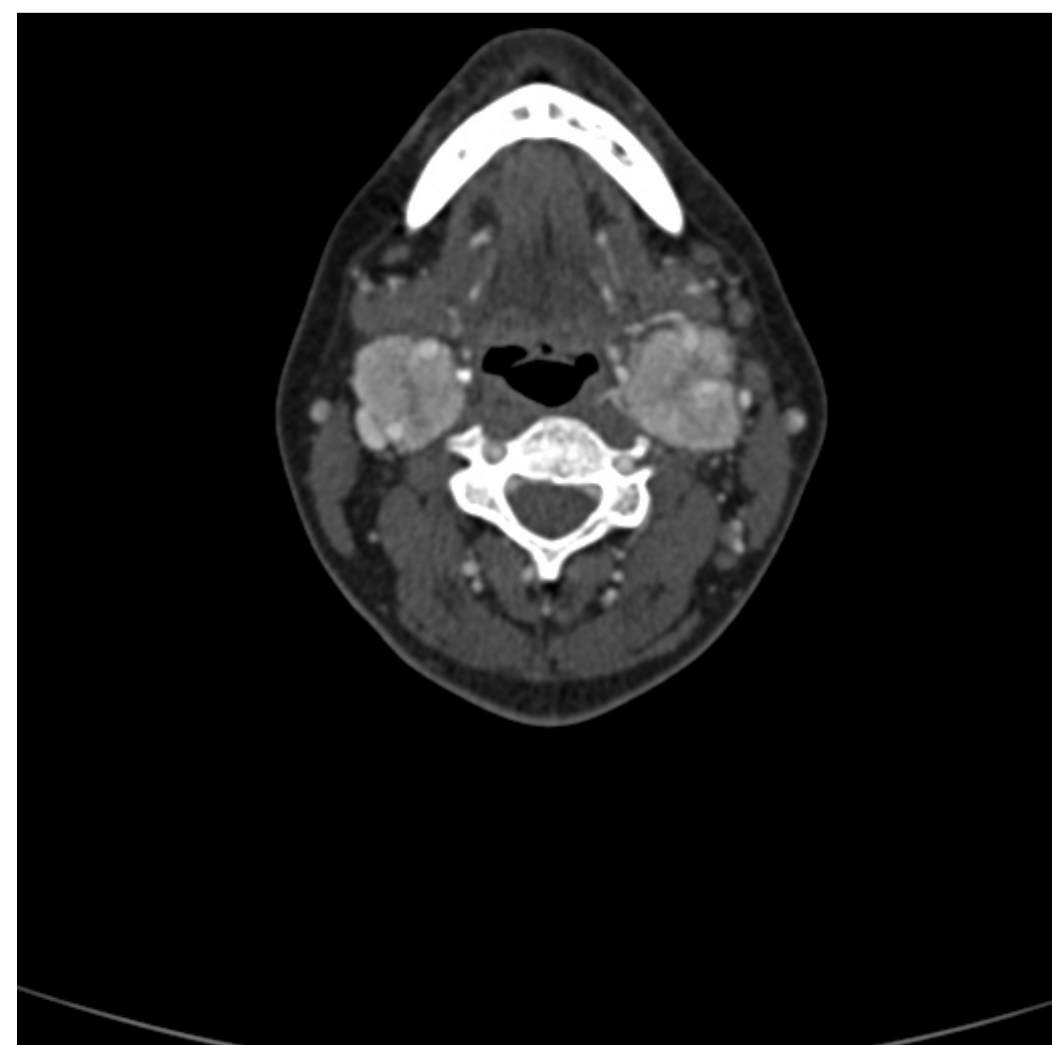

Figure-3: CT angiography axial view showing intensely enhancing masses in bilateral submandibular regions with splaying of carotid vessels

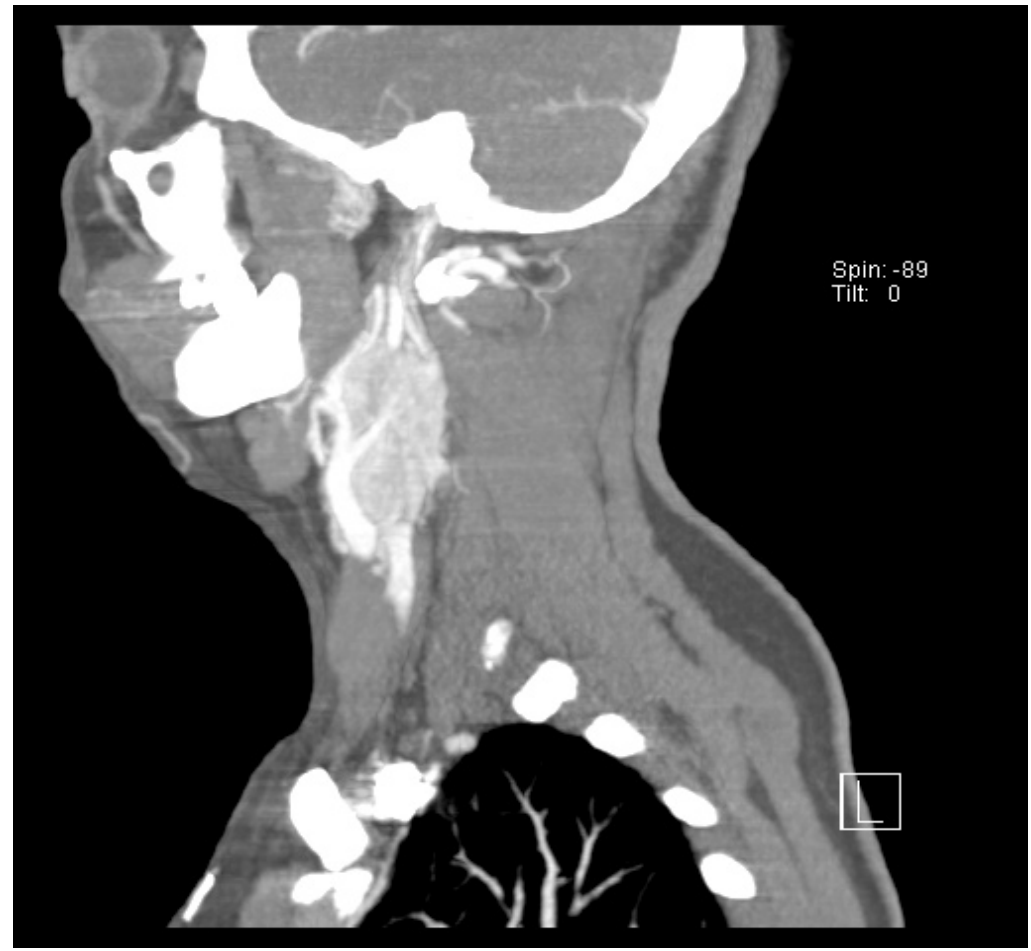




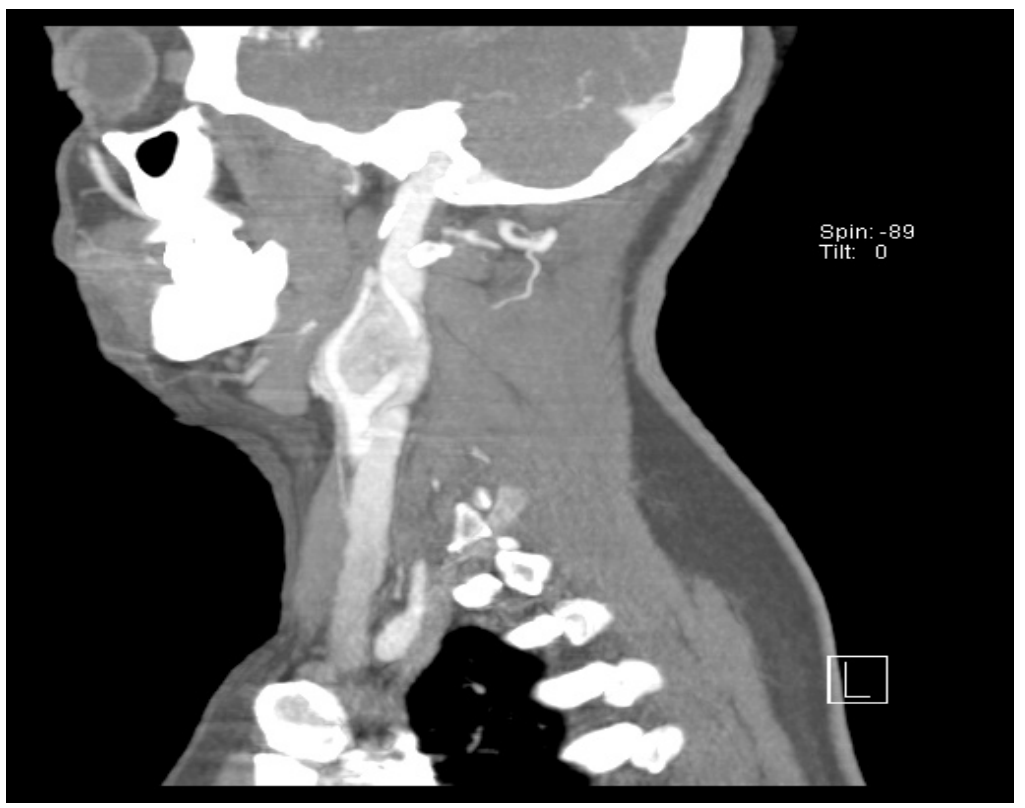

Figure-4: Sagittal CT angiographic section through the neck showing enhancing soft tissue masses in right and left carotid region causing displacement and splaying of vessels. On MRI, the nature \& anatomical relations of the lesions were further characterised.

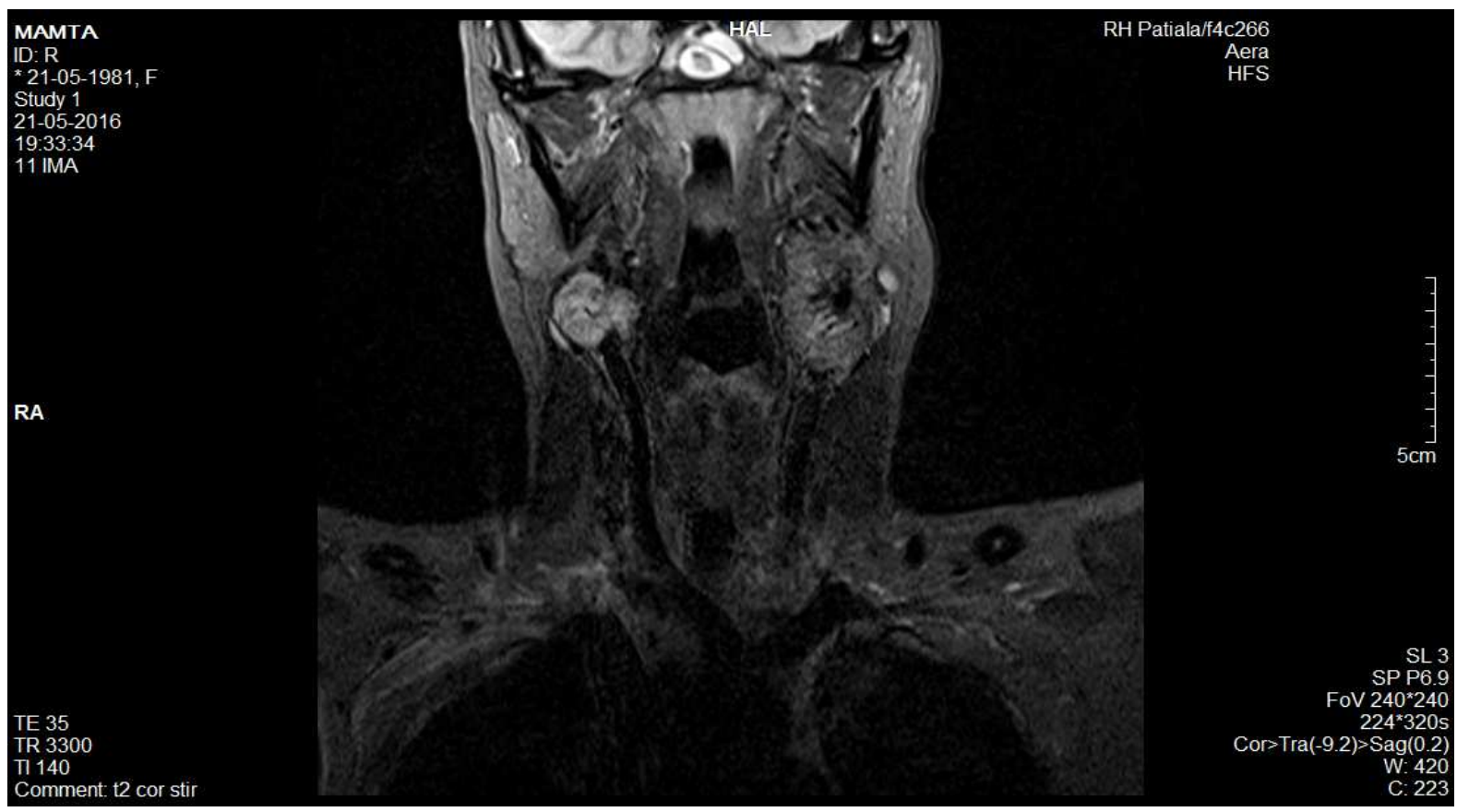

Figure 5: Coronal T2 weighted fat sat MR image showing bilateral carotid region masses with isointense signal intensity and displacing the carotid vessels. Few areas of hypointensities are noted within the masses that can be ascribed to "salt and pepper appearance" appreciated well on the left side.

Final diagnosis of bilateral carotid body tumours was done keeping in view of all imaging findings. The patient was referred to higher centre for further management.

\section{Discussion}

Bilateral carotid tumours are a very rare presentation of extra- adrenal paragangliomas [5]. Haller was thought to have discovered the carotid body tumour in 1742 , however the first accurate description was given by 
Mayer in 1833[6]. The exact cause is unknown, though theories exist regarding hypoxia and genetic factors as predisposing factors [7]. The most common age group affected is 4 th -5 th decade, the incidence being more in females. Sporadic form is the commonest with bilateral tumours seen in $10 \%$ of cases. Less common is the familial form with $\mathrm{AD}$ inheritance and multicenteric tumours may be seen in $35-50 \%$ cases [5].

The patients usually present with asymptomatic neck masses, often increasing in size. Other manifestations include headache, neck pain, buzzing, dizziness, hoarseness, dysphagia, syncope and cranial nerves involvement particularly vagus, hypoglossal \& glossopharyngeal nerves $[3,4]$. Other differentials include nodal mass, brachial cyst, carotid aneurysms, metastatic carcinomas, intravagal tumours and ectopic thyroid [8].

Imaging with ultrasound scan shows the exact location and size of mass and is a convenient \& non invasive method. Usually this mass is isoechoic and located just at carotid bifurcation. Colour Doppler imaging shows the hyper vascular nature of the mass and peripherally splayed ICA and ECA. Three dimensional imaging modalities like Computerized Tomography as well as Magnetic Resonance Imaging can better delineate the location and number of tumors and involvement of skull base, pharynx or jugular vein [1].

On CT images, a carotid tumor is identified as a welldefined soft tissue mass within the carotid sheath with a homogeneous enhancement. Larger tumors may be inhomogeneous due to necrotic and hemorrhagic changes. The ECA is usually displaced anteromedially and the ICA is typically displaced posterolaterally, which strongly indicates a diagnosis of CBT [5]. Digital subtraction angiography (DSA) is considered the gold standard and it demonstrates dense blush of the hyper vascular tumour situated at the carotid bifurcation [1].

Treatment options include surgery or radiotherapy depending on bilaterality, patient's age \& fitness, presence of other paragangliomas and patient's choice [9]. Larger tumours may need pre-operative embolisation [10].

To conclude, carotid tumours can be a rare but important and life threatening differential diagnosis in patients with asymptomatic neck masses. Timely diagnosis can prevent fatal complications due to blind interventions and save the patient.

\section{Funding: Nil, Conflict of interest: None. Permission of IRB: Yes}

\section{References}

1. Georgiadis GS, Lazarides MK, Tsalkidis A, Argyropoulou P, Giatromanolaki A. Carotid body tumor in a 13-year-old child: Case report and review of the literature. J Vasc Surg. 2008 Apr;47(4):874-880. doi: 10.1016/j.jvs.2007.10.040. Epub 2008 Feb 14.

2. Grotemeyer D, Loghmanieh SM, Pourhassan S, Sagban TA, Iskandar F, Reinecke P, Sandmann W. [Dignity of carotid body tumors. Review of the literature and clinical experiences]. Chirurg. 2009 Sep;80(9):854-63. doi: 10.1007/s00104-009-1724-x.

3. Hallet Jr JW, Nora JD, Hollier LH, J. Cherry Jr KJ, Pairolero PC. Trends in neurovascular complications of surgical management for carotid body and cervical paragangliomas: a fifty-year experience with 153 tumors. J Vasc Surg. 1988 Feb;7(2):284-91.

4. Glenner GG, Grimley PM. Tumors of the extraadrenal paraganglion system. In: Atlas of Tumor Pathology, second series, fasc 9. Washington, Armed Forces Institute of Pathology; 1974.

5. Lee KY, Oh YW, Noh HJ et-al. Extraadrenal paragangliomas of the body: imaging features. AJR Am J Roentgenol. 2006 Aug;187(2):492-504.

6. Heath D. The human carotid body in health and disease. J Pathol. 1991 May;164(1):1-8.

7. Kyriakos, M., Pathology of Selected Soft Tissue Tumors of the Head and Neck in: Comprehensive Management of Head and Neck Tumors; Thawley, S.E., Panje, W.R. eds.; Philadelphia PA.W.B. Saunders; 1987; 1261-4.

8. Meyer FB, Sundt Jr TM, Pearson BW. Carotid body tumors: a subject review and suggested surgical approach. J Neurosurg. 1986 Mar;64(3):377-85.

9. Li-Shan L, Chang-Wei L, Heng G, Yue-Hong Z, Xing-Ming C, Yong-Jun L. Efficacy of surgical therapy for carotid body tumors. Chin Med Sci J. 2011 Dec;26(4):241-5. 
10. Sahin MA, Jahollari A, Guler A, Doganci S, Bingol H, Karaman B, et al. Results of combined preoperative direct percutaneous embolization and surgical excision in treatment of carotid body tumors. Vasa. 2011 Nov;40(6):461-6. doi: 10.1024/0301-1526/a000149.

\section{How to cite this article?}

Pawar NC, Sharma S, Kaur NK, Kaur A. Asymptomatic bilateral chemodectomas: a masquerader of simple neck masses. Int J Med Res Rev 2017;5(01):20-25. doi:10.17511/ijmrr. 2017.i01.03 